Revista Complutense de Historia de América

ISSN: $1132-8312$

http://dx.doi.org/10.5209/RCHA.56728

\title{
Interpretar la corrupción: el marqués de Villarrocha, Capitán General de Panamá (1698-1717)
}

\author{
Francisco Andújar Castillo²
}

Recibido: 1 de febrero de 2017 / Aceptado: 27 de marzo de 2017

Resumen. Los estudios sobre historia de la corrupción en la monarquía hispánica se han venido realizando a partir de documentación judicial y de la generada por los denominados mecanismos de control -visitas, juicios de residencia y pesquisas- que se pusieron en marcha para verificar la acción de los agentes de gobierno. En esta aportación mostramos que la documentación emanada de esos instrumentos de control es fundamental, pero insuficiente para investigaciones que suelen estar marcadas por la complejidad. Tomamos como referencia el caso de José Antonio Rocha Carranza, marqués de Villarrocha, quien a finales del siglo XVII, tras comprar el puesto de Capitán General de Panamá y Presidente de la Audiencia, fue procesado en tres ocasiones por el Consejo de Indias por acusaciones de corrupción, condenado en primera instancia las tres veces, pero finalmente absuelto de todos los cargos que se le imputaban. Frente a una interpretación del caso que podría hacerse en clave de luchas de facciones y de poder entre Villarrocha y los oidores o miembros del cabildo que le habrían denunciado, el imprescindible cruce de fuentes documentales, en concreto con una fuente ajena a los procesos judiciales, revela que la corrupción presidió su acción de gobierno durante las tres etapas en que ocupó el citado cargo. Igualmente planteamos los problemas de método que se suelen suscitar en investigaciones relacionadas con las citadas fuentes documentales.

Palabras clave: Corrupción; fuentes documentales; marqués de Villarrocha; Consejo de Indias; Panamá; siglos XVII-XVIII.

\section{[en] Interpreting Corruption: the Marquis of Villarrocha, Captain General of Panama (1698-1717)}

\footnotetext{
Abstract. Studies on the history of corruption in the Hispanic monarchy have usually been based on judicial documentation and other documents generated by the so-called mechanisms of control - visits, residence judgments and investigations - that were created to verify the government agents' action. This article demonstrates that the documentation emanating from these instruments of control is fundamental, but insufficient for research into a theme that is usually marked by complexity. The case of José Antonio Rocha Carranza, Marquis of Villarrocha, serves as a reference. After achieving the position of Captain General of Panama and President of the Audiencia at the end of the seventeenth century, Villarocha was accused of corruption three times by the Council of the Indies, convicted in the first instance in all three cases, but finally acquitted of all charges. Faced with the task of interpreting the case in terms of the factional and power struggles between Villarrocha and the oidores or members

$1 \quad$ El presente estudio se ha realizado en el marco del Proyecto de Investigación de I+D Entre venalidad y corrupción en la Monarquía Hispánica durante el Antiguo Régimen (HAR2014-55305-P), financiado por el Ministerio de Economía y Competitividad.

2 Universidad de Almería (España)

E-mail: fandujar@ual.es
} 
of the Cabildo who denounced him, the indispensable cross-referencing of documentary sources -in particular with a source from outside of the judicial processes- reveals that corruption presided over Villarocha's government action during the three periods in which he occupied the above-mentioned position. Likewise, we lay out the methodological problems that tend to arise in investigations related to the aforementioned documentary sources.

Keywords: Corruption; Documentary Sources; Marquis of Villarrocha; Council of the Indies; Panama; 17-18th Centuries.

Sumario. 1. Introducción. 2. Fuentes documentales para historiar la corrupción. 3. Juan Antonio Rocha Carranza, marqués de Villarrocha ¿Insigne matemático, Capitán General de Panamá, fundador del cuerpo de Artillería, traficante de esclavos? 4. Tres veces Capitán General de Panamá, tres veces depuesto y absuelto. 5. ¿Fue un corrupto el marqués de Villarrocha? El problema de las fuentes documentales. 6. El problema del método de investigación: la red familiar. 7. A modo de conclusión. 8. Referencias bibliográficas.

Cómo citar: Andújar Castillo, F. (2017) Interpretar la corrupción: el marqués de Villarrocha, Capitán General de Panamá (1698-1717), en Revista Complutense de Historia de América 43, 75-100.

\section{Introducción}

Los estudios sobre las prácticas relacionadas con la corrupción en la monarquía hispánica entre los siglos XVI y XVIII han tenido un gran auge en los últimos años, especialmente para el caso de la América colonial, territorio que por diversas razones, que son hoy día objeto de un interesante debate historiográfico, conoció un intenso desarrollo de dinámicas de "mal gobierno" por parte de los agentes del rey, instalados tanto en las más altas instancias políticas, caso de los virreyes ${ }^{3}$, como en las diferentes escalas de gobierno -gobernadores, corregidores, alcaldes mayores, capitanes generales-, pasando desde luego por las magistraturas de justicia ${ }^{4}$. Una extensa producción se ha ocupado del problema, aunque desde dos perspectivas muy distintas, que van desde quienes tienen un concepto laxo de las dinámicas relacionadas con la corrupción, hasta quienes niegan la misma por entender que es un mero anacronismo la aplicación de categorías y conceptos tomados de la actualidad a un pasado en el que los actores sociales tenían una percepción muy distinta de lo que era lícito e ilícito, o de lo que era el buen y mal gobierno.

Recientemente uno de los ejes de ese debate gira en torno al concepto de corrupción en el Antiguo Régimen. Las aportaciones recientes de Pilar Ponce Leiva ${ }^{5}$, Anne Dubet $^{6}$, Michel Bertrand ${ }^{7}$, o Adriana Romeiro ${ }^{8}$, entre otras, han puesto el acento en los problemas interpretativos del concepto y su significación en el contexto de la época. No en vano, la preocupación por una aproximación a la definición del concepto de corrupción comienza a estar presente en numerosas investigaciones, hasta el punto que no es infrecuente encontrar en estudios de caso, o de coyunturas, introducciones previas, a veces de modo autojustificativo, acerca de lo que el autor entiende por corrupción y las diversas interpretaciones que la historiografía ha dado sobre

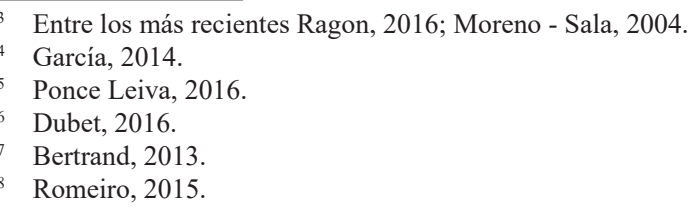


el término9 ${ }^{9}$ En todo caso, en el horizonte se vislumbran dos posiciones claras, una que parte de una perspectiva amplia sobre el término "corrupción" y su aplicación a sociedades del Antiguo Régimen, y otra que se asienta en una visión restrictiva, que a menudo niega la existencia de prácticas corruptas por considerar que el historiador está trasladando categorías de la sociedad actual al análisis del pasado. Una tercera vía sería la que, con acierto, diferencia corrupción y relaciones de patronazgo, si bien algunos estudios todavía continúan confundiendo ambos conceptos. Las discusiones llegan a ser tan amplias que exceden al propio concepto, e incluso llegan a formularse propuestas como la que desde Alemania postula "una nueva historia de la corrupción", fundamentada precisamente en los problemas de definición del fenómeno ${ }^{10}$.

No obstante, hay que considerar que si ni siquiera hoy día existe pleno acuerdo acerca de lo que se entiende por corrupción, más complicada se nos antoja la tarea cuando nos referimos al pasado, máxime si, además, ese pasado alude a monarquías absolutas. Lo que parece totalmente superado ya, en el marco de ese debate, es la negación de la existencia del propio término de "corrupción" en los discursos y textos de la monarquía hispánica. Por el contrario, como demuestran algunos de los últimos estudios, existía con las mismas acepciones y connotaciones que le otorgamos en la actualidad, al menos desde el siglo XVII ${ }^{11}$.

A pesar de la proliferación de estudios en los últimos años, resta aún mucho camino por desbrozar, pues perviven aún grandes vacíos, tanto territoriales como cronológicos, e incluso existen aspectos que parecen haber quedado al margen de la preocupación de los historiadores, caso por ejemplo del mundo militar ${ }^{12} \mathrm{o}$ eclesiástico, cuyas prácticas de enriquecimiento constituyen un fascinante campo de investigación ${ }^{13}$. Entre los vacíos historiográficos más sonoros cabe individualizar el análisis del mecenazgo artístico desde la perspectiva económica, es decir, desde el estudio de los procesos de acumulación de capitales por vías poco lícitas que convirtieron a muchos individuos en protectores y promotores de las artes. En otros términos, consideramos que se deberían plantear estudios en paralelo a los que abordan los historiadores del Arte, analizando los casos, no tanto desde la óptica del mecenazgo, como desde las formas de captación de capitales por parte de aquellos individuos -fundamentalmente los que desempeñaron cargos al servicio de la monarquía- que se convirtieron en grandes mecenas, y que, con toda probabilidad, llevaron a cabo esa labor como un signo más de la riqueza acumulada. Sin duda, una valiosa cantera de estudios podría tener su punto de partida en los trabajos que se vienen haciendo sobre la América colonial desde la Historia del Arte ${ }^{14}$.

Por otro lado, existe pleno acuerdo entre la comunidad científica en considerar la venalidad de cargos como un proceso ajeno por completo a aquella. Tanto las ventas de oficios impulsadas por la monarquía como las transferencias de empleos perpetuados entre particulares -y que por ende constituían bienes enajenables en su calidad de propiedades privadas- fueron procesos plenamente institucionalizados, reglados, y que funcionaron a lo largo de la Edad Moderna como un mecanismo más de nombramiento de agentes de la monarquía. Solo es posible observar fronteras entre la

\footnotetext{
Victoria, 2015.

Rosenmüller - Ruderer, 2016: 11.

Ponce Leiva, 2016: 195; Andújar, en prensa a.

Entre las escasas excepciones véase Reyes Cárdenas, 2013.

Un ejemplo de dinámicas de este tipo puede verse en Andújar - Giménez, 2011.

14 Entre las aportaciones más recientes véase Rodríguez - Fernández - López, 2016.
} 
venalidad y la corrupción en tres casos: cuando quien compraba un cargo trataba de amortizar la inversión recurriendo a procedimientos de "mal gobierno"; cuando el dinero abonado por la adquisición de un cargo no tenía como destino una tesorería del rey sino el bolsillo particular de quien había sido comisionado para enajenarlo; $\mathrm{y}$, relacionado con esto último, cuando quien vendía lo hacía en nombre del rey para obtener beneficios personales sin tener legitimidad para ello. Por tanto, la frontera más evidente estaría entre los procesos venales y el cohecho.

En cualquier caso, en este apresurado balance historiográfico, por lo que hace a los métodos de investigación sobre las prácticas de corrupción en el mundo americano, no hay duda alguna de que el enfoque predominante es el del estudio del caso individual, probablemente el único posible, dada la complejidad de la tarea investigadora. Sin embargo, consideramos que se hace necesario avanzar en dos direcciones contrapuestas. De una parte, pasar del estudio de casos al análisis microhistórico, en el estricto sentido del término, como lo hicieran en su día los historiadores italianos, y lo ha explicitado una extensa producción en torno a esta tendencia historiográfica ${ }^{15}$. De otro lado, la suma de estudios de casos, debería ir posibilitando la elaboración de análisis transversales sobre algunas problemáticas de investigación relacionadas con la historia de la corrupción, de modo que se pudiesen ir dando pasos hacia formulaciones que permitieran obtener algunas pautas generales sobre dinámicas comunes en cronologías concretas.

En nuestra opinión, el estudio del amplio espectro de ámbitos relacionados con la corrupción -cohechos, sobornos, malversación de caudales públicos, concusión, "excesos", etcétera- debe afrontar en el futuro tres retos relacionados con: la necesidad de precisar los problemas conceptuales en busca de un acuerdo terminológico, aplicar una metodología específica de investigación y, vinculada con esta última, proceder a una adecuada interpretación de las fuentes documentales, de manera que estas vayan más allá de los conocidos instrumentos de control de los agentes de gobierno.

\section{Fuentes documentales para historiar la corrupción}

Precisamente sobre las fuentes documentales y los consiguientes problemas de interpretación que algunas de ellas plantean, versa esta aportación. Se trata de una reflexión sobre las posibles lecturas de las fuentes más usuales para conocer las dinámicas de corrupción, y que no son otras que las derivadas de los mencionados "instrumentos de control", esto es, visitas, juicios de residencia, pesquisas y tomas de cuentas, a las que habría que sumar los procesos judiciales, tanto los derivados de los resultados de esos "controles" como aquellos que se incoaron como consecuencia de denuncias interpuestas ante los tribunales de justicia.

De partida, señalemos que no todos los servidores del rey estuvieron sometidos a esos controles, incluso, ni siquiera los que debían ser más normalizados, los juicios de residencia, llegaron a evaluar la acción de gobierno de todos los agentes de la monarquía que sirvieron en América, pues muchos de ellos lograron quedar exentos de esas inspecciones, bien por gracia real, bien por el pago de un servicio pecuniario. Aunque los juicios de residencia han sido una fuente esencial para conocer las prácticas relacionadas con la corrupción, las críticas hechas en los últimos años a

15 Aguirre, 2014. 
esas residencias, en el fondo vienen a poner en cuestión la fiabilidad misma de la documentación emanada de esos juicios. Para Tamar Herzog, las residencias más que instrumentos de control se articularon como ritos, como espacios de comunicación en los que la administración, la jurisdicción y la paz social trataban de ser recreadas, circunstancias que explican que buena parte de ellas acabaran terminando con resoluciones favorables a los residenciados ${ }^{16}$. A pesar del eco que ha tenido esta visión antropológica de los juicios de residencia, más allá de la finalidad última de las residencias, lo cierto es que con demasiada frecuencia la documentación generada por esos procesos se ha convertido en el único elemento de estudio.

Como es obvio, y como sucede con otras fuentes similares, no es posible hacer historia a partir de una fuente parcial, condicionada por su propio proceso de construcción, y por el papel central del "instructor", casi siempre el sucesor en el cargo del residenciado, factores todos ellos que invitan a pensar que, por lo general, se trata de una fuente que tan solo permite aproximarnos de modo indiciario a lo que fue una acción de gobierno. A pesar de esta evidencia, de forma reiterada se siguen haciendo estudios que se limitan a desmenuzar la documentación generada por el juicio de residencia, sin contrastar o, en propiedad, cruzar esa fuente con otros registros documentales ${ }^{17}$. En este sentido, por ejemplo, no parecen haber tenido demasiado calado las inequívocas conclusiones que sacara en su día Alfredo Moreno cuando mostró cómo el marqués de Castelfuerte, virrey del Perú entre 1724 y 1736, salió indemne de su juicio de residencia y fue calificado como hombre honesto que había obrado con gran desinterés, en tanto que el cruce con otras fuentes documentales lo reveló como un gobernante que aprovechó su cargo para enriquecerse utilizando procedimientos claramente ilícitos ${ }^{18}$.

El cruce de fuentes documentales debería ser principio esencial del quehacer del historiador pero, como se observa en numerosas publicaciones, no parece que siempre sea el eje vertebrador mínimo del método ${ }^{19}$. Siempre es más sencillo y eficaz evocar tan solo el discurso que nos transmite "la fuente" que, por lo general, además, suele ser la fuente "pública", es decir, la conservada en los archivos estatales, ignorando a menudo que las "fuentes privadas" tienen gran utilidad, en especial cuando se precisa reconstruir las actividades económicas, el patrimonio, las formas de acumulación de capital, los negocios particulares, su interrelación con los cargos públi$\cos \mathrm{y}$, en suma, todo lo que conformaría en la trayectoria de cualquier individuo su decurso vital. Todos esos elementos son fundamentales a la hora de estudiar aspectos tan decisivos como los nexos entre el ejercicio de cargos públicos y la obtención de beneficios de ellos para lucro personal ${ }^{20}$. A veces, ni siquiera es preciso acudir a esas fuentes documentales de carácter privado, por lo que produce auténtica perplejidad constatar cómo se publican trabajos sobre la base de una sola fuente documental -el caso de los juicios de residencia o de las visitas resulta paradigmático- cuando en el mismo archivo que se ha obtenido esa fuente se pueden hallar otros registros sobre el mismo tema estudiado.

\footnotetext{
Herzog, 2000.

Ejemplos de ese modelo pueden verse en Álamo, 2015; Torres, 2015.

Moreno, 2004: 160.

19 Una problemática similar se plantea en relación a los estudios sobre venalidad de cargos y honores. Véase al respecto Andújar, 2012.

20 Un ejemplo reciente de esa interrelación puede verse en Braddick, 2016.
} 
Si el cruce de diversas fuentes documentales en torno a un mismo caso debería ser algo consustancial al oficio de historiador, más necesario aún se hace cuando se trata de investigar fenómenos relacionados con el cohecho, la malversación, la concusión u otras prácticas de "mal gobierno". La razón de esa mayor necesidad radica en que, por lo general, esas prácticas no suelen encontrarse siempre de manera explícita en la documentación, antes al contrario, difícilmente se pueden observar huellas cuando los propios actores sociales eran conscientes de que de cualquier actividad ilícita no debía quedar rastro escrito alguno.

La complejidad de la investigación sobre esas prácticas de "mal gobierno" es mayor aún cuando de documentación judicial se trata, y cuando el historiador se encuentra ante resoluciones absolutorias o condenatorias dictadas por un tribunal o, en el caso de América, su más alta magistratura, el Consejo de Indias. Partiendo del principio de que nunca el historiador debe de hacer de juez, aseveración que no parece ser compartida por cierta historiografía apegada exclusivamente a la supuesta "veracidad" absoluta del documento, las fuentes judiciales pueden inducir, tanto de forma directa como indirecta, a posicionarse en uno $u$ otro lado de la balanza -exculpatorio o condenatorio- a la hora de analizar la actividad de cualquier agente de la monarquía durante su etapa de gobierno o de ejercicio profesional. A pesar de ello se cuentan por decenas los estudios que, siguiendo una visita o un juicio de residencia, hablan tanto de corrupción como de gobernantes ejemplares. Por fortuna, desde posiciones metodológicas radicalmente distintas, algunos investigadores construyen la historia desde otros postulados que se alejan del recurso a la fuente única. Así, por ejemplo, si acudiésemos al juicio de residencia de Tomás Marín de Poveda, Capitán General de Chile y Presidente de su Audiencia entre abril de 1692 y 1699, deduciríamos que fue un hombre honesto y celoso en el cumplimiento de las tareas de su cargo, pues salió libre de cargos del juicio de residencia a que fue sometido muchos años después de su muerte, acaecida en octubre de $1703^{21}$. Sin embargo, las investigaciones recientes de Antonio Rodríguez Ridao demuestran justamente lo contrario, que sus prácticas corruptas -robos- en torno al situado del ejército de Chile presidieron su gestión durante sus años de gobierno ${ }^{22}$.

Sobre estos fundamentos pretendemos exponer en las páginas que siguen un estudio de caso complejo, el del marqués de Villarrocha, Capitán General de Panamá en tres ocasiones sucesivas en las postrimerías del siglo XVII, quien fue enjuiciado, condenado y luego absuelto finalmente las tres veces por el Consejo de Indias. Una ingente masa documental se conserva en el Archivo General de Indias sobre esos procesos, e incluso el propio marqués se encargó de imprimir varios defensorios -porcones- en los que se exculpaba de cuantas acusaciones se hicieron sobre las actividades ilícitas que le llevaron a ser encausado e incluso depuesto de su cargo. El tema excede, con mucho, los límites del formato de un artículo. No obstante, trataremos de sintetizarlo para mostrar la diferente perspectiva de la historia que se obtiene cuando se manejan unas u otras fuentes documentales. En este caso, cruzaremos esa documentación judicial con otra de carácter privado, ajena esta última por completo a la generada por esos procesos judiciales pero que, en última instancia, de forma

\footnotetext{
21 Residencia de Tomás Marín de Poveda, gobernador y Capitán General del reino de Chile y Presidente de su Audiencia por Gabriel Cano de Aponte. 1717. Archivo General de Indias [España] (en adelante AGI), Escribanía, 941 A.

22 Rodríguez Ridao, 2017.
} 
indirecta, arroja más luz sobre lo que fue la realidad del marqués de Villarrocha durante el tiempo que desempeñó la Capitanía General de Panamá.

\section{Juan Antonio Rocha Carranza, marqués de Villarrocha ¿Insigne matemático, Capitán General de Panamá, fundador del cuerpo de Artillería, traficante de esclavos?}

Las interrogantes que figuran en el enunciado del epígrafe son las informaciones que hasta la fecha la historiografía nos permite conocer acerca de la persona de Juan Antonio Rocha Carranza, marqués de Villarrocha. Como se comprobará pueden parecer algunas de ellas hasta contradictorias entre sí, por lo que conviene ampliarlas, aun de forma muy sucinta.

El padre fray Benito Feijoo, en su conocido Teatro Crítico Universal publicado en 1730 escribía:

Hoy está en la misma Corte el señor Marqués de Villarrocha, septuagenario, Presidente que fue de Panamá, y ha cuatro años que vino del Mar del Sur por las Filipinas, y el Cabo de Buena-Esperanza a Holanda. Es insigne Matemático, e instruido en toda buena literatura. Conserva en tan avanzada edad no sólo una gran entereza y agilidad intelectual, más también un humor muy fresco y una viveza graciosísima ${ }^{23}$.

En efecto, la afición a las matemáticas, al menos en los últimos años de su vida, parece innegable pues entre sus bienes contabilizó al hacer testamento "una tabla en que tiene escrito diferentes curiosidades de Astrología, un cajón lleno de instrumentos de Matemática y un estuche chico de lo mismo" "24. Sin embargo, su biblioteca, apenas contenía unos cuantos libros, la mayoría de "devociones", si bien contaba con dos obras clásicas de la Astrología, las Efemérides de Andrea Argoli y dos libros de Juntino de Florencia sobre la misma materia.

En todo caso, si por algo ha pasado a la historia este personaje, más que por las tres ocasiones en que ocupó el puesto de Capitán General de Panamá, ha sido por dos acontecimientos de su trayectoria vital ajenos por completo a ese cargo. Por orden cronológico, el primero de ellos sucedió en el año 1704 cuando intervino como "financiero" en la formación de un regimiento de artillería -en propiedad "Fusileros Reales para el servicio de la Artillería" -, con ocasión de la creación de nuevas unidades militares que tuvo lugar durante los primeros años de la Guerra de Sucesión. Esa intervención en la leva de dicho regimiento motivó que muchos historiadores le consideraran el "fundador de la Artillería" en España, al ser la primera vez que se creaba una unidad específica para dicha arma. Sin embargo, como mostramos en su día en otro estudio, aquella fue una empresa mercantil que exigió un elevado coste, al tratarse de un regimiento de características especiales -1200 soldados, reclutados, vestidos y armados a su costa- por lo que antes de presentar su propuesta a Felipe V, formó una sociedad mercantil con un personaje bien introducido en la hacienda real,

Feijoo, 1753: 101

24 Testamento del Sr. Marqués de Villarrocha. Madrid, 20-II-1730. Archivo Histórico de Protocolos de Madrid [España] (en adelante AHPM), Protocolo 16.040, f. 92r. 
el financiero holandés Huberto Hubrecht, quien intervino como fiador y principal pagador de la contrata que el marqués de Villarrocha ofrecía al rey ${ }^{25}$. A cambio de ese servicio este último obtendría el sueldo y título de "General de la Artillería", el grado de coronel del nuevo regimiento y las patentes en blanco de la oficialidad para su particular venta con el fin de enjugar parte del coste de aquella inversión o, en su caso, incluso obtener beneficios de la enajenación de esos despachos. En la contrata se incluyó una cláusula secreta, desaparecida hoy del expediente, que probablemente podría haber explicado el efímero papel desempeñado por el marqués al frente del regimiento, pues no parece que estuviera mucho tiempo al mando del mismo, aunque sí conservó el título de "General de la Artillería". Tal vez esa cláusula secreta aludiera a que capituló en dicha contrata que gozaría a perpetuidad de los sueldos de General de la Artillería y de coronel del regimiento que levantaba ${ }^{26}$. En todo caso, según una memoria anexa a su testamento, fechada en Madrid el 20 de febrero de 1730 , habría invertido en la formación de aquel regimiento la considerable suma de 86.000 pesos $^{27}$.

Aquel fue uno de los negocios de Villarrocha con el citado financiero, aunque no debió ser el único, pues años después, en 1707, otro socio de Hubrecht, Bartolomé Flon, uno de los banqueros más destacados de los primeros años del reinado de $\mathrm{Fe}-$ lipe V, reclamó al marqués de Villarrocha una deuda de 79.000 pesos cuyo impago le obligó a dejar el cargo de Capitán General de Panamá28. Según $\mathrm{M}^{\mathrm{a}}$ Teresa Muñoz Serrulla, Bartolomé Flon servía como testaferro de Hubrecht durante estos años ${ }^{29}$. El nexo de Villarrocha con estos hombres de negocios holandeses debió estar relacionado con el tráfico de esclavos, pues Hubrecht fue uno de los accionistas de la Compañía de Guinea y del Asiento que desde julio de 1701 se hizo con el monopolio de la introducción de negros en las colonias españolas ${ }^{30}$. No en vano el marqués pudo actuar como un agente de esa compañía en defensa de los intereses franceses en el tráfico de esclavos en Panamá. El estudio de Reyes Fernández Durán sobre el tráfico de esclavos señala que el marqués de Villarrocha compró el puesto de Panamá con dinero de Hubrecht para que defendiese los intereses franceses y no pusiese ninguna dificultad al funcionamiento de la compañía del asiento de negros, de modo que fueron precisamente las autoridades francesas las que pidieron a España que se le reintegrase a su puesto en Panamá tras su primer cese ${ }^{31}$. Por otro lado, documentos fechados en 1708 lo describían como un personaje que apoyaba de forma secreta el contrabando que de forma abierta se ejercía por parte de los españoles en el Caribe ${ }^{32}$.

La tesis de Fernández Durán es verosímil, aunque parcialmente, pues la compra del cargo de Capitán General de Panamá fue previa a la constitución de la Compañía de Guinea en 1701. No obstante acierta de pleno acerca del papel desempeñado por Villarrocha en ese negocio. Al respecto la documentación diplomática francesa de los primeros años del reinado de Felipe V es muy clara. En mayo de 1702, Bartolomé Flon escribía al embajador de Francia en España, el conde de Marcin, en términos

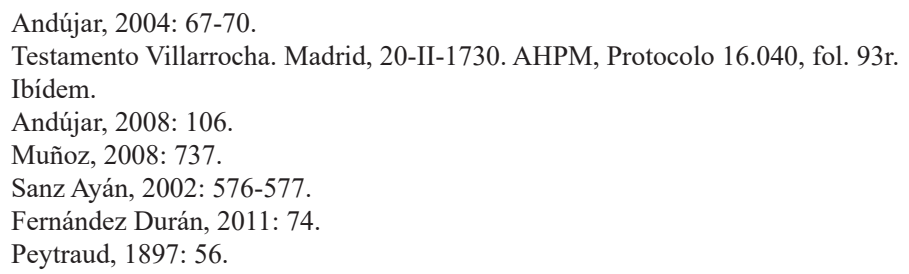


tan inequívocos como que le llamaba "nuestro marqués de Villarrocha", y afirmaba que "de él depende nuestra continuación y también el servicio de S.M." 33 . Al año siguiente, en el mes de julio, el nuevo embajador de Luis XIV en la corte de Madrid, el cardenal d'Estrées, se interesó tanto por la situación judicial del marqués de Villarrocha que en carta dirigida a su monarca le informó que le había dado a Felipe V "las razones que tiene para tratarlo bien", y que el marqués debía ser restituido en el gobierno del que había sido "injustamente desposeído" 34 . Los intereses de Francia en el asiento de negros se verían, sin duda, favorecidos por la presencia en Panamá de un hombre de la clientela de los financieros holandeses, a su vez, partícipes en dicho asiento. Y de ahí el interés de los embajadores en que tuviera resoluciones judiciales favorables y que fuese restituido en el cargo del que por entonces acababa de ser destituido por vez primera.

A pesar de todo, el episodio más conocido hasta ahora en la trayectoria vital del marqués de Villarrocha fue su apresamiento, junto a su esposa y esclavos, por el corsario inglés Clipperton a finales de enero de 1720, cuando viajaba en el navío Nuestra Señora del Carmen desde Panamá rumbo hacia el puerto de El Callao. Siendo como es una "historia de piratas", las versiones contradictorias, y alguna que otra fabulación, han proliferado por doquier en diversas publicaciones. El asunto, aunque adquirió tintes casi novelescos, sigue aún repleto de interrogantes, sobre todo en lo relativo a cómo se desarrolló su liberación, así como la de su esposa, doña Teresa Manrique de Lara. Por tanto, optamos por anotar la versión del protagonista, recogida en su testamento. Según la misma, cuando regresaba a España el día 29 de enero del citado año, al ser apresado por Clipperton, este le quitó cuantos bienes portaba. Pero su descripción del acontecimiento no la hacía para narrar su desdicha sino la de su esposa, la cual había sido arrojada, junto a su familia, por el corsario, a "una playa desierta al arbitrio de las fieras, en la jurisdicción de Guatemala" "35. La esposa sería rescatada por un oidor de Guatemala, Ambrosio Tomás Santaella Melgarejo, quien la llevó luego consigo a México cuando fue promovido a oidor de la Audiencia de la capital del virreinato, y allí permanecería hasta su muerte, pues jamás regresó a España. El marqués de Villarrocha sería liberado en las islas Marianas por el corsario inglés hacia mediados de 1721, según consta en una carta remitida a Madrid por el fiscal de la Audiencia de Manila, Pedro de Bedoya ${ }^{36}$.

La versión de aquellos sucesos fue ampliada por su propia mujer el mismo año de su apresamiento al reclamar a la Audiencia de Guatemala sus derechos sobre el navío en donde viajaba cuando fue hecha presa junto a su marido. Teresa Manrique precisó que en dicha embarcación viajaba toda la familia y sus esclavos, y que el marqués de Villarrocha pactó con el corsario la liberación de todos los capturados a cambio de 25.000 pesos, pero éste se arrepintió y navegó un largo tiempo hasta el puerto de Velas, en la provincia de Nicoya, en busca de soltar lastre para tratar de encontrar tres cajas de plata ocultas que, según la marquesa de Villarrocha, no halló, y de cuya existencia habría informado al corsario inglés el propietario del navío, Agustín de Carranza $^{37}$. Una nueva negociación con Clipperton, mediante el pago de otro rescate,

\footnotetext{
33 Carta de Bartolomé Flon al conde de Marcin. Madrid, 11-V-1702. Ministère des Affaires Étrangères, París [Francia] (en adelante MAE), Correspondance Politique d'Espagne (en adelante CPE), 104, f. 153.

Carta del cardenal d'Estrées a Luis XIV. Madrid, 25-VII-1703. MAE, CPE, 124, f. 469v.

Testamento Villarrocha. Madrid, 20-II-1730. AHPM, Protocolo 16.040, f. 78v.

Carta de Pedro de Bedoya a Andrés de Elcorobarrutia. Manila, 10-VII-1721. AGI, Filipinas, $171, \mathrm{n}^{\circ} 9$.

Gagini, 1924: 245.
} 
hizo que liberara a la marquesa en Nicoya, no en la playa desierta al arbitrio de las fieras que describiera el marqués. Por último, esa misma información de la marquesa de Villarrocha, desvelaba que el origen de la delación del dueño del navío radicaba en que su marido había prestado más de 22.000 pesos para la carena y que para no devolvérselos, Carranza le había acusado de llevar en el lastre oculta la plata. Por todo ello, por haber prestado esa suma, la marquesa se consideraba legítima propietaria del navío en que había sido apresada junto a su marido y familia.

El episodio, al margen de la casuística concreta de la captura del marqués de Villarrocha por el corsario inglés, revela la existencia de un personaje acaudalado, con capacidad económica como para sufragar la carena del navío en el que iba a viajar a España, con recursos suficientes para pagar su rescate, y que posiblemente transportaría en dicho navío una cierta cantidad de plata. Veamos ahora cómo pudo acumular ese capital.

\section{Tres veces Capitán General de Panamá, tres veces depuesto y absuelto}

José Antonio Rocha Carranza había nacido en Quito en junio de 1657 en el seno de una familia acomodada, pues era hijo de Diego Andrés Rocha, oidor de aquella ciudad -luego lo sería de Lima- ${ }^{38}$, quien ha pasado a la historia por su conocida obra sobre El origen de los indios, publicada en Lima en $1681^{39}$. Los primeros años de su vida nos son prácticamente desconocidos, si bien sabemos que en el momento de adquirir el cargo de Capitán General de Panamá y Presidente de la Audiencia, en junio de 1698 , por la considerable suma de 45.000 pesos $^{40}$, decía tener unos exiguos servicios de cinco años y medio en las plazas de soldado y capitán de infantería, tiempo que tampoco podía acreditar de forma fehaciente pues según su relación de servicios había "perdido" esa documentación en un naufragio ${ }^{41}$. Analizando ese doble título de nombramiento, en el que desde luego no se hacía mención alguna al pago de esa cantidad, se puede constatar que estaban implícitos los aprovechamientos "ilícitos" de los cargos, por cuanto se le fijaba un salario anual de 4.500 pesos para un periodo de ocho años de ejercicio que suponían un monto de 36.000 ducados, cantidad inferior a los 45.000 pesos que había pagado al adquirir ambos cargos ${ }^{42}$.

Ignoramos de dónde pudo sacar tan cuantiosa suma para adquirir el cargo, aunque tenemos la certeza de que no fue aquella la única cantidad que manejó por esos años. $\mathrm{Su}$ presencia en la Corte la documentamos por vez primera en el año 1692 cuando a mediados de año formaliza escrituras notariales en las que, por un lado, hacía entrega de caudales que le habían dado en Lima para que fuesen abonados a personajes influyentes en el entorno cortesano -en concreto un ayuda de cámara del rey y regidor de Madrid llamado Gonzalo Pacheco-, y por otro, hace préstamos a un indiano que

38 Su trayectoria se encuentra en Lohmann Villena, 1974: 188-189.

39 Rocha, 1681.

40 Sanz Tapia, 2009: 222. Según su relación de méritos y servicios de 1703, el empleo lo habría conseguido el 25 de octubre de 1697 -ocultando, claro está, que el mérito radicaba en el grueso servicio pecuniario de los 45.000 pesos- si bien el despacho de Capitán General de Panamá y de Presidente de su Audiencia se le dio con fecha de 25 de junio de 1698. Relación de méritos y Servicios. Madrid, II-1703. Real Academia de la Historia, Madrid [España] (en adelante RAH), Ms. 70822, f. 1v.

41 Relación de méritos y servicios. Madrid, II-1703. RAH, Ms. 70.822, f. 1r.

42 Título de nombramiento de José de la Rocha y Carranza de Gobernador y Capitán General de las provincias de Tierra Firme y Veragua. Madrid, 25-X-1698. AGI, Contratación, 5796, Lib. 1, ff. 110r-116v. 
precisaba el dinero para su viaje de regreso a Perú ${ }^{43}$.

Ese mismo año de 1692 consigue hacerse con una merced de hábito de caballero de la orden de Calatrava "en atención a sus servicios" 44 que, dada la exigüidad de los mismos, con toda certeza debió proceder del tráfico privado de mercedes que por entonces se desarrollaba en los aledaños de palacio ${ }^{45}$. El estudio detallado sobre cómo se hizo con el hábito calatravo, sobre los testigos que depusieron en sus pruebas para ser armado caballero, daría para una aportación monográfica pues podría considerarse como modelo de las redes de poder y de corrupción que funcionaban por entonces en torno a la obtención de los hábitos de las órdenes militares. Incluso ese estudio podría relacionarse con otro espacio de ascenso social, el inquisitorial, en el que también participaría años después Rocha Carranza cuando se hizo con una familiatura de la inquisición ${ }^{46}$, pues no en vano en su relación de méritos del año 1703 se intitulaba como Ministro Oficial de la Santa y Suprema General Inquisición. No obstante, el medro social lo culminaría aquel año de 1703, cuando consiguió el título de marqués de Villarrocha por un más que extraño procedimiento, pues supuestamente en ese año lo que hizo fue cambiar la denominación de marqués de Rocha que se le había dado en 1698 a un abuelo suyo -paradójicamente el mismo año que compró el puesto de Capitán General de Panamá- y rehabilitarlo con el nombre de marqués de Villarrocha ${ }^{47}$. Lo interesante del caso es que en las informaciones genealógicas que había presentado unos años antes para ser investido como caballero de Calatrava, el hipotético abuelo que recibiera el título de marqués de la Rocha no fue esgrimido como "mérito familiar" el buen manejo de la red de relaciones que supo tejer en la Corte. De un modo u otro, lo cierto es que con fecha de 17 de julio de 1703 se le expidió el despacho del título nobiliario de marqués de Villarrocha, aunque años atrás ya se intitulaba como tal ${ }^{49}$.

En 1698, cuando adquiere el puesto de Capitán General de Panamá, negocia en Madrid otros asuntos que ponen de manifiesto que atesora por entonces grandes caudales. Así, por ejemplo, lo encontramos comprando uno de los denominados "efectos de Madrid" -deuda municipal emitida por el ayuntamiento- ${ }^{50}$ o prestando dinero a indianos para sus pretensiones de cargos y honores ${ }^{51}$. Durante ese mismo año, bien introducido ya en los asuntos de palacio y en las covachuelas en donde se movían intereses de todo orden, también prestó dinero a familiares residentes en Indias para similares "pretensiones" 52 .

43 Escrituras de obligación firmadas por José Antonio Rocha Carranza. Madrid, 1692. AHPM, Protocolo 10.555, ff. 70r., 248r., 430r. y 438r.

44 Expediente para la concesión del Título de Caballero de la Orden de Calatrava de José Rocha de Carranza. 1692. Archivo Histórico Nacional, Madrid [España] (en adelante AHN), Órdenes Militares, Expedientillo 11378.

45 Andújar, en prensa $b$.

46 Información genealógica de José de la Rocha Carranza, caballero de la Orden de Calatrava, natural de San Francisco de Quito (Ecuador) y pretendiente a familiar del Tribunal de la Inquisición de Corte. Madrid, 1696. AHN, Inquisición, 1276, exp. 3.

47 Libro registro de títulos. AHN, Consejos, Lib. 2753.

48 Expediente de pruebas para la concesión del Título de Caballero de la Orden de Calatrava de José Rocha de Carranza. 1692. AHN, Órdenes Militares, Calatrava, exp. 2229.

49 Real Despacho de marqués de Villarrocha. Madrid, 17-III-1707. AHN, Consejos, 8976, exp. 154.

50 Cesión por parte de Diego Luis de San Vítores a José Antonio Rocha Carranza de un efecto de 55.000 reales de principal contra la villa de Madrid. Madrid, 1-IV-1697. AHPM, Protocolo 13.093, f. 527v.

51 Poder de Carlos Alcedo al marqués de Villarrocha. Madrid, 10-V-1698. AHPM, Protocolo 13.806, f. 176.

52 Obligación otorgada por Gabriel Ordóñez a favor del marqués de Villarrocha de 6.000 pesos. Madrid, 14-VIII1698. AHPM, Protocolo 13806, f. 186r. 
Una vez adquirido el cargo de Panamá, José Antonio Rocha Carranza partió hacia su destino tomando posesión del mismo el día 7 de julio de $1699^{53}$. Sin embargo, cuando apenas había comenzado a servir el cargo ya había salido desde Madrid una orden para que fuera suspendido del mismo. La orden, dirigida al conde de la Monclova, virrey del Perú, fechada el 14 de agosto de 1699, mandaba que no se le diera posesión del cargo, "por no tener aún experiencia militar", que se le devolviesen en las cajas de Lima los 30.000 pesos -recuérdese que otras fuentes hablan de 45.000 pesos- con que había servido por dicho empleo y se le retirasen sus títulos ${ }^{54}$. Esa misma orden mantenía como gobernador interino al conde de Canillas, anterior Capitán General, hasta que terminase la operación de desalojo de los escoceses de Darién. Como es obvio, la orden tardó en llegar a Portobelo y no fue suspendido del cargo hasta el día 21 de diciembre de 1699. Razones no faltaban en Madrid para apartarle de un empleo que había adquirido, como la gran mayoría de los que se servían entonces en América merced al pago de servicios pecuniarios, siendo a menudo éste el único mérito para hacerse con esos cargos. Y es que se había nombrado Capitán General de Panamá a un individuo con una cortísima -casi nula- experiencia militar y se le había enviado a un territorio que acababa de sufrir la invasión escocesa en la zona de Darién ${ }^{55}$.

De esos cinco meses que sirvió el cargo de Capitán General pronto llegaron hasta el Consejo de Indias numerosas acusaciones contra Rocha Carranza, quien ya se titulaba como marqués de Villarrocha a pesar de que el título nobiliario no lo obtendría, como hemos señalado, hasta el año 1703. En efecto, en 1700 comienzan a dictarse en el Consejo de Indias los primeros autos judiciales en su contra por haber participado de forma activa en el contrabando durante el corto periodo de tiempo que sirvió el cargo. El propio conde de Canillas inició el expediente informativo contra el marqués de Villarrocha, su sobrino José Ordoñez, Miguel del Ollo y otros sujetos, por haber participado en contrabando con una embarcación francesa que entró en la ciudad de Portobelo ${ }^{56}$. En julio de 1703 se comisionó a Jerónimo de Córdoba, oidor de la Audiencia de Panamá, para que procediera contra el marqués de Villarrocha en causa de comiso ${ }^{57}$. Pero justo cuando se dictó esa comisión, el marqués ya se había fugado de Tierra Firme y había emprendido un largo y complicado periplo para llegar hasta Madrid, pues había logrado escapar de la cárcel de Portobelo para partir hacia Jamaica en un navío inglés, y de allí a Londres, más tarde a Bruselas, de ahí a París y finalmente a Madrid en donde fue hecho preso de nuevo. En noviembre de 1701 ya se encontraba en la cárcel de la Corte en donde se le tomó declaración acerca de los cargos que se le imputaban. Justo un año después el Consejo de Indias dictó sentencia por la que se le condenaba a la privación del derecho que pudiese tener a ser restituido en la presidencia de Panamá y a la devolución de la cantidad de dinero que desembolsó por el cargo, al tiempo que se le prohibía en lo sucesivo desempeñar

53 Relación de méritos y servicios. Madrid, II-1703. RAH, Ms. 70822, f. 1v.

54 Orden al virrey del Perú participándole la providencia que se da para el gobierno de Panamá. Madrid, 14-VIII1699. AGI, Panamá, 243, lib. 2, f. 158r.-162v.

55 Agradezco a Alfonso Jesús Heredia López su inestimable ayuda para reconstruir algunos aspectos de los procesos judiciales que se sustanciaron en el Consejo de Indias contra el marqués de Villarrocha.

56 Autos hechos por el señor Conde de Canillas y de Torneros, del consejo supremo de Indias, presidente gobernador y Capitán General de este reino de Tierra Firme, contra el señor marqués de Villa Rocha, su sobrino y otros. 1700. AGI, Escribanía, 473 A y 473 B.

57 Orden a don Jerónimo de Córdoba para proceder contra el marqués de Villarrocha y demás culpados en una causa de comiso. Madrid, 3-VII-1701. AGI, Panamá, 232, lib. 10, f. 56r. 
puesto alguno que tuviese administración de justicia. Sin embargo, en junio de 1703 una nueva sentencia de revista del Consejo de Indias lo absolvió de los cargos que se le imputaban, al tiempo que se ordenaba desembargar todos los bienes que se le habían embargado como consecuencia de la sentencia de vista anterior ${ }^{58}$. Esa nueva sentencia lo dejaba en libertad, a la vez que se le reconocía el derecho, bien a ser restituido en la presidencia de la Audiencia de Panamá y su Capitanía General, bien a percibir el dinero que pagó al beneficiar dicho cargo.

A partir de ese momento la historia del perdedor se transforma de modo súbito en la de un ganador. Es cuando consigue el despacho del título de marqués y cuando obtiene, en 20 de diciembre de 1703, una nueva orden de Felipe V por la que se le restituía en la presidencia de Panamá en caso de que faltare o sufriere un accidente quien por entonces la servía, y mientras eso sucedía, se le confería la presidencia que antes vacase de las Audiencias de Guatemala, Chile o Charcas ${ }^{59}$. Para que el honor que había sido mancillado por la sentencia anterior quedase restituido, la Gaceta de Madrid se ocupó de difundir la exculpación de los cargos por los que había sido condenado con anterioridad al publicar la orden de restitución en el puesto comprado de Capitán General de Panamá ${ }^{60}$. El éxito continuaría en los meses siguientes. Como señalamos más arriba, fue en enero de 1704 cuando en sociedad con el financiero holandés Huberto Ubrecht ofreció formar el regimiento de artillería. Fue también la época en que amplió sus negocios y relaciones con otros financieros como el mencionado Bartolomé Flon, futuro conde de la Cadena.

El segundo episodio del marqués de Villarrocha y la presidencia de la Audiencia de Panamá y su Capitanía General se inicia el 8 de mayo de 1707 cuando habiéndose trasladado de nuevo a Tierra Firme toma posesión de esos $\operatorname{cargos}^{61}$. Sin embargo poco tiempo le iba a durar la alegría de la restitución en el cargo porque una nueva orden fechada en octubre de ese mismo año, y firmada con el sello secreto del rey, ordenaba de nuevo su destitución a causa de una deuda que mantenía con Bartolomé Flon por importe de 79.000 pesos $^{62}$. A la sazón, el financiero holandés era uno de los hombres más poderosos de la monarquía por sus estrechas relaciones y amistad con el embajador francés Michel Amelot, por su condición de prestamista del rey y por el destacado papel que jugó como intermediario en la vasta operación venal que tuvo lugar por aquellos años ${ }^{63}$. Según el propio marqués de Villarrocha, la deuda procedía del préstamo que Flon le hizo para pagar los gastos de la leva del regimiento de $\mathrm{Fu}$ sileros Reales de Artillería. Por tanto, se produjo lo que el propio marqués de Villarrocha denominó como "segundo despojo" de la presidencia de Panamá, al ser apre-

58 Sentencia dada en el pleito y causa contra José Antonio de la Rocha Carranza. Madrid, 12-VI-1703. AGI, Escribanía, 960 .

59 Órdenes a la Secretaría de Justicia. Madrid, 20-XII-1703. Archivo General de Simancas [España] (en adelante AGS), Gracia y Justicia, 21, f. 439r.

60 Gaceta de Madrid, $\mathrm{n}^{\circ} 1,1-\mathrm{I}-1704,4$.

${ }_{61}$ El general de Artillería, Coronel de Fusileros Reales, Don Joseph Antonio de la Rocha y Carranza, Caballero del Orden de Calatrava, Marqués de Villa-Rocha, Gobernador y Capitán General del Reyno de Tierra Firme, y su Presidente de la Real Audiencia, y Chancillería de Panamá, y Provincia de Veraguas, puesto a los Reales pies de V.M. dize le precisa la obligación de administrar la honra de sus Mayores, y la propia suya, representar a V.M. se halla tercera vez despojado de la Presidencia de Panamá, y para que V.M. se entere de lo ocurrido en su dependencia, hará sucintamente relación desde el origen de que se le hizo merced de ella. 1725. Biblioteca Nacional de España (en adelante BNE), Porcones, 231-2, f. $2 r$

62 Carta a la Audiencia de Panamá participando lo que escribe Don Fernando José de Haro, oidor de ella. Madrid, 21-XII-1709. AGI, Panamá, 232, lib. 10, ff. 42 r.-424v.

63 Andújar, 2008: 102-108. 
sado por dos oidores de la Audiencia que él mismo presidía. En diversos castillos de Panamá estuvo preso más de tres años, tiempo durante el cual nuevamente le iban a llover las acusaciones contra su efímera gestión. Ya en el mismo mes de octubre de 1707 había sido multado con 2.000 pesos por haber permitido "con acuerdo de la Audiencia”, que dos balandras francesas entrasen en Portobelo para vender esclavos ${ }^{64}$.

Un nuevo proceso judicial, el segundo, se abrió a partir de entonces en el Consejo de Indias, tras haber pasado el caso por la Audiencia de Lima. Interpretado todo por el propio marqués en clave de su enfrentamiento con los oidores de Panamá, el virrey del Perú, vistos los autos en justicia, declaró por nulo todo lo hecho y haberse cometido "violento e irreverente despojo", ordenando que se restituyesen al marqués todos sus bienes y papeles pagándole todos los sueldos que hubiese devengado. No obstante, esa decisión no suponía su restitución en el cargo, por lo que a finales de 1711 emprendió nuevo periplo de regreso a la Corte, esta vez más accidentado que al anterior, pues acabó varando el barco donde venía en el Cabo de San Vicente el 12 de febrero de 1712, perdiendo todo cuanto tenía y fue hecho prisionero de guerra hasta el 20 de agosto del mismo año ${ }^{65}$. Mientras que esos acontecimientos se sucedían, en el Consejo de Indias desde el año 1709 se le había abierto un nuevo proceso judicial en el que se le hicieron diversos cargos contra su corta gestión al frente de la Capitanía General de Panamá, entre ellos el de haber detenido los galeones que viajaban hacia España y haber separado sin orden del rey 400.000 pesos del tesoro real que portaban esos galeones para la paga de soldados ${ }^{66}$. Pero al igual que sucediera la primera vez que fue procesado, una real cédula fechada en 28 de julio de 1710 mandaba al oidor de Lima, Juan Bautista Orueta, quien ejercía de forma interina la presidencia de Panamá, que el marqués de Villarrocha fuese liberado de prisión y fuese restituido en el uso y ejercicio de sus empleos, debiendo cesar en ellos en cuanto llegase a Panamá su sucesor, José Hurtado de Amezaga ${ }^{67}$. Al mismo tiempo se ordenaba que los oidores que le habían apresado, Francisco José de Zúñiga y Fernando José de Haro fuesen privados de sus empleos y traídos presos hasta la Casa de Contratación de Sevilla en los primeros navíos que partiesen hacia España. La resolución real consideraba que había sido despojado violentamente de la presidencia de Panamá y que debía ser restituido en su cargo, aunque por poco tiempo, pues ya había sido designado para sustituirle un militar de experiencia, José Hurtado de Amezaga, nombrado en abril de 1709, pero que no partió hacia Panamá hasta el año siguiente. La noticia de su restitución viajó en el mismo barco en el que iba su sustituto, y así el 22 de junio de 1711 el marqués de Villarrocha fue repuesto en sus cargos pero Hurtado de Amezaga tomó posesión de los mismos al día siguiente ${ }^{68}$.

La absolución definitiva de las acusaciones que se le habían hecho durante su segundo mandato en Panamá llegó en noviembre de 1713, cuando una nueva resolución del Consejo de Indias lo declaró por libre de todas las acusaciones. Y al igual

64 Orden a los oficiales reales de Panamá para que saquen 2.000 pesos de multa al marqués de Villarrocha por haber permitido a dos balandras de corso francesas diferentes presas. Madrid, 27-XI-1708. AGI, Panamá, 232, lib. 10 , ff. $348 \mathrm{v} .-350 \mathrm{r}$.

65 El general de Artillería, Coronel de Fusileros Reales, 1725. [...]. BNE, Porcones, 231-2, f. 2v.

${ }^{66}$ El señor fiscal de S.M. con el señor marqués de Villarrocha, presidente, gobernador y Capitán General que fue de Panamá sobre comercios ilícitos y otras cosas. Panamá, 1708. AGI, Escribanía, 474A.

67 Real Orden a don Juan Bautista de Orueta, presidente interino de Panamá. Madrid, 28-VII-1710. AGI, Panamá, 232, lib. 10, ff. 449r.-454r.

68 Sala, 2004: 119. 
que sucediera en 1704 nuevamente la Gaceta de Madrid se encargó de pregonar la feliz noticia de la absolución del marqués de Villarrocha ${ }^{69}$. No solo fue absuelto sino que además se ordenó que fuese restituido en la Presidencia de Audiencia y Capitanía General de Panamá, y que fuesen desembargados todos sus bienes y castigados los citados oidores que le habían acusado, decisión que se había tomado ya en julio del año $1710^{70}$.

Llegamos así al tercer episodio o mandato del marqués de Villarrocha en Panamá, y al "tercer despojo" o cese en sus cargos. Nuevamente viajó hacia Tierra Firme y el 26 de febrero de 1716 tomó posesión de la Presidencia y Capitanía General de Panamá, permaneciendo en ellos hasta el día 12 de diciembre de $1717^{71}$. Una vez más no pudo alcanzar siquiera el año de gobierno pues con extraordinaria celeridad se le volvió a abrir en Madrid un nuevo proceso por "excesos" cometidos en el uso de sus empleos. Una real orden fechada el 10 de septiembre de 1717 -por tanto, cuando apenas llevaba poco más de seis meses en el cargo- le mandaba regresar a Madrid cesando en todos sus cargos. Esta vez el enfrentamiento no había sido con los oidores de la Audiencia de Panamá sino con el cabildo de la ciudad. No obstante, los cargos no fueron esos solos sino muchos más, un total de quince. Los sintetizó muy bien el propio marqués de Villarrocha en el Memorial Ajustado del proceso que se siguió en su contra en el Consejo de Indias ${ }^{72}$. Algunos de ellos tenían que ver con su acción de gobierno (no tener bien abastecidos de pólvora y municiones las tropas y castillos de Panamá, o haber quitado los empleos a algunos oficiales de las cajas reales) pero la mayoría tenían relación directa con lo que eran "excesos" o actividades claramente ilícitas: haberse quedado con parte del situado -dinero que se remitía desde la caja de Lima para el pago de los soldados- de 50.000 pesos que había remitido el virrey, Príncipe de Santo Buono; especular con las raciones de pan que debía dar a los soldados comprando la harina a precios muy inferiores de los que luego la vendía a los militares; dedicarse al contrabando de géneros prohibidos con extranjeros valiéndose de testaferros; obligar a los guardas que vigilaban los caminos en Panamá y Portobelo a que cobraran por cada carga ciertas sumas de dinero que iban a parar a los bolsillos del marqués; utilizar los mismos procedimientos con los barcos que conducían víveres y frutos, a los cuales no les daba licencia si no contribuían pagándole "tasas" ilegales; utilizar los negros del rey que se tenían para la guarda de ganado y otros fines para su servicio personal; haberle quitado al propietario de la mina de oro de Mariprieta los negros que trabajaban en ella; no haber ingresado en las cajas reales un donativo que hicieron los mercaderes de Panamá para reparo de las murallas; haber vendido a los vecinos aguardiente procedente de una urca inglesa; $y$, por último, haber obligado a un escribano a falsificar y suplantar hojas de su escribanía.

Como se comprueba, la nómina de delitos era demasiado amplia, en especial para tan corto tiempo de mandato pues, como vimos, esta tercera etapa no había llegado

69 Gaceta de Madrid, $n^{\circ} 45,7-X I-1713,180$

70 Cédula a la Audiencia de La Plata mandando ejecuten lo ordenado sobre privación de empleo de su oidor Francisco José de Zúñiga. Madrid, 28-VII-1710. AGI, Buenos Aires, 4, lib. 13, ff. 132v.-135r.

71 Memorial ajustado del pleito que en este Real y Supremo Consejo de las Indias se sigue entre el señor doctor Don Tomás de Sola, fiscal en dicho Real Consejo por lo tocante al reino del Perú, con el General de la Artillería Don Joseph Antonio de la Rocha y Carranza, Caballero del Orden de Calatrava, Marqués de Villa-Rocha, Gobernador y Capitán General que fue de la Provincia de tierra Firme y su Presidente en la Real Audiencia y Chancillería de la ciudad de Panamá en el reino del Perú. Madrid, circa 1725. BNE, Porcones, 231 (1), f. 2r.

72 Ibídem. 
a los seis meses de duración. Como sucediera en anteriores ocasiones, acatando la decisión real regresó a España y fue entonces cuando lo hizo prisionero el corsario inglés Clipperton. De todos modos, de esa larga nómina de acusaciones logró salir indemne, también por tercera vez. En abril de 1725 el marqués de Villarrocha imprimió el citado Memorial Ajustado en el que se defendía de esos cargos, y el 4 de septiembre de ese mismo año el Consejo de Indias pronunció la sentencia absolutoria de todos sus cargos con la única advertencia de que no "volviese a comprar harina extranjera" 73 .

\section{5. ¿Fue un corrupto el marqués de Villarrocha? El problema de las fuentes documentales}

Tres veces Capitán General y Presidente de Audiencia, tres veces cesado, tres veces encausado y tres veces absuelto. Y todo ello tras haber ejercicio el cargo durante unos meses en cada una de esas etapas ¿Fue cesado por corrupción el marqués de Villarrocha o fue víctima de los intereses de otros poderes que operaban en Panamá como los oidores, los miembros del cabildo o las elites mercantiles? ¿Fue encausado por delitos cometidos en el ejercicio de su cargo o realmente las denuncias vinieron de parte de los que competían con él en los intereses económicos que se movían en torno a Portobelo y Panamá? ¿Fue absuelto porque pudo probar ante el Consejo de Indias su inocencia ante los cargos que se le imputaban?

El historiador cuenta para analizar el caso en profundidad con una masa documental que aporta la perspectiva de los hechos desde tres puntos de vista. Por un lado, las acusaciones de cuantos cargos se le imputaron durante su etapa de gobierno y que constan en los procesos judiciales que se incoaron en el Consejo de Indias. Se trata de una ingente documentación que se conserva completa en el Archivo General de Indias. Por otro lado, se cuenta con otro interesante caudal de documentos generado por el propio interesado, el marqués de Villarrocha, en forma de defensorios legales, de alegaciones a sus procesos, que se encargó de imprimir -y probablemente de distribuir- para probar su inocencia ante las acusaciones que sufrió durante las tres etapas en que estuvo al frente de las dos principales instituciones de gobierno y justicia de Panamá. Estos porcones vienen a ser la síntesis de los procesos judiciales, aunque aportando la particular perspectiva de quien encargaba su impresión para la defensa de sus intereses. En suma, se podría tratar de reconstruir el caso con una completísima documentación que muestra la historia desde los dos lados, el de quienes le acusaban, y los argumentos contrarios del acusado. Por otro lado, el Consejo de Indias le declaró libre de cuantas acusaciones le llevaron a perder el cargo y a dar con sus huesos en prisión hasta en tres ocasiones. Por tanto, según la justicia, el marqués de Villarrocha, habría sido una víctima de los oscuros intereses de quiénes le acusaron de haber realizado en sus cortos mandatos actividades "corruptas".

Como señalamos más arriba, a pesar de contar con abundantes fuentes de información, creemos que siempre será posible otra historia, no solo de este caso del marqués de Villarocha, sino de cualquier otro que se investigue, cuando se acceda a fuentes documentales de carácter privado, generadas por intereses ajenos a los

73 Sentencia de revista dada en la causa seguida por el señor fiscal del Consejo contra el marqués de Villarrocha. Madrid, 20-X-1725. AGI, Escribanía, 964. 
existentes en los procesos judiciales que buscaban siempre la defensa del encausado. Veamos pues qué sucedió en el caso concreto de Villarrocha al cruzar las abundantes fuentes documentales, generadas como consecuencia de los procesos judiciales, con una fuente "privada", aunque se conserva en un archivo notarial y, por ende, público.

El 25 de febrero de 1730 el marqués de Villarrocha, cinco días después de haber hecho testamento, y justo un mes antes de su muerte, hizo ante escribano de Madrid una Declaración de todos los efectos que tengo en los reinos de Indias, partes del Perú y todo lo demás que en ella se expresa (en adelante, Declaración) ${ }^{74}$. El excepcional documento contiene mucho más de lo que su título indica, pero es ante todo el ajuste de las cuentas que el marqués mantenía con su sobrino Bernabé Felipe de Aragón y una extensa nómina de individuos con los que había mantenido negocios y le adeudaban caudales. La segunda parte del mismo viene a ser un minucioso inventario de los bienes que conservaba en su casa madrileña. A pesar de que el documento fue redactado muchos años después de su rocambolesca trayectoria en Panamá, conserva numerosas referencias a aquella etapa.

El sobrino, Bernabé Felipe, debió tener una trayectoria cercana a la de su afamado -en lo judicial- tío. Sus actividades y cargos fueron tan diversos como que permitirían realizar un amplio estudio monográfico. Por el momento, anotemos tan solo algunos registros relacionados con los cargos que ocupó o, en propiedad, compró. Según Sanz Tapia, en noviembre de 1680 consiguió por sus servicios previos el corregimiento de la Paz, pero en 1687 obtendría por un servicio pecuniario, esto es, por beneficio, de 5.000 pesos, el corregimiento de Cochabamba y justo diez años después el de Huamalíes, por "subrogación" -traducimos nosotros, por "compra privada"- a Juan Hurtado de Quesada ${ }^{75}$. Su propio tío, en la Declaración recordó la cantidad de 6.000 pesos que abonó para conseguir ese cargo ${ }^{76}$. Durante el tiempo en que ejerció el corregimiento de Cochabamba, por haber comerciado, fue condenado al pago de 20.000 pesos y a la privación del empleo, pero años después, en noviembre de 1706, fue indultado, seguramente mediando un servicio pecuniario de menor importe al de la condena pecuniaria ${ }^{77}$.

Por tanto, ya sabemos por qué se adquirían los cargos y qué actividades podían proporcionar ingresos muy superiores a los sueldos inherentes a esos puestos. La figura del gobernador / corregidor dedicado al comercio en el espacio de su jurisdicción debió estar extendida durante aquellas últimas décadas del siglo XVII -y probablemente mientras duró la venalidad hasta $1750-^{78}$ en que se vendían al mejor postor los puestos de gobierno, justicia, hacienda y milicia. Pero el caso de Bernabé Felipe de Aragón debió moverse en una escala de lo ilícito muy inferior a la que practicara su tío.

La Declaración revela, con incontestable claridad, los "aprovechamientos" que podían obtener quienes compraban los cargos de gobierno político en América. El marqués de Villarrocha no aludió directamente a la compra de la Capitanía General de Panamá -más allá de ratificar que pagó por ella 45.000 pesos- pero sí a los

\footnotetext{
74 Declaración del marqués de Villarrocha en 15 de febrero de 1630, Madrid (en adelante, Declaración 1630). AHPM, Protocolo 16040, ff. 84r.-95r.

75 Sanz Tapia, 2009: 412.

76 Declaración 1630. AHPM, Protocolo 16.040, f. 85r

77 Libro registro de decretos de partes. AGS, Estado, Lib. 421. Sobre los indultos en estos años véase Andújar Gil, 2015.

78 Andújar, 2016: 77.
} 
beneficios que las actividades ilícitas podían reportar a quienes desempeñaban los cargos públicos, o lo que es lo mismo, cómo el poder que otorgaban esos cargos era el fundamento principal del ejercicio de otras actividades ajenas que podían reportar pingües beneficios. Así, en referencia al corregimiento de Huamalíes, al ajustar las cuentas con su sobrino, no tuvo problema alguno para afirmar que le debía aún los 6.000 pesos más sus intereses, y los 500 pesos correspondientes a los despachos del título que le prestó para que lo adquiriera, y que "siendo un oficio que en cinco años reditúa más de 400.000 pesos, aviendo v.m. obtenido ocho, le habrá valido más de 600.000 pesos, con que es justo se satisfaga partida por partida [...]"79. Si esas sumas se contrastan con el sueldo anual que percibía un corregidor de Huamalíes, que era por entonces de 1.000 pesos ensayados de a 12,5 reales $^{80}$, se aprecia la considerable diferencia con los beneficios anuales de 80.000 pesos que, según el marqués de Villarrocha, se podían obtener, evidentemente por vías extrasalariales, es decir, no lícitas. Sin duda, la rentabilidad era alta para un oficio que había costado 6.000 pesos para ejercerlo durante cinco años. Y es que de los oficios no se obtenían salarios sino que se "sacaban" rendimientos. Lo reiterará el mismo marqués de Villarrocha en ese ajuste de cuentas al referirse al corregimiento de La Paz, también ejercido por Bernabé Felipe, al firmar que durante los cinco años de desempeño de ese oficio "no se pueden sacar $^{81} 100.000$ pesos" $\$$.

Por entonces, la mayor parte de los oficios de gobierno político de América constituían un gran espacio de oportunidad para el enriquecimiento personal por medio de múltiples actividades ilícitas, y no eran ni mucho menos simples cargos de servicio a la monarquía. Eran antes que nada cargos en los que la "corrupción" permitía ganancias a quienes los ejercían, con las lógicas diferencias de posibilidades de aprovechamiento que había entre unos y otros, y que se reflejaron con meridiana claridad en su cotización en el enorme mercado venal que se abrió en la Corte a partir del año 1674. El marqués de Villarrocha no le compró a su sobrino Bernabé Felipe de Aragón el corregimiento de Huamalíes para que ejerciera un cargo de prestigio y honor, sino porque este último le aseguró previamente "que lo que se ganase lo partiríamos entre los dos" ${ }^{\prime 3}$. Esa ganancia, como es obvio, nunca fue el salario sino los aprovechamientos ilícitos del ejercicio del cargo.

Pero haciendo referencia precisa al tiempo que el marqués de Villarrocha estuvo al frente de la Capitanía General de Panamá, más arriba hemos visto cómo fue acusado de especular con la harina que suministraba a los soldados, acusación que negaría ante el Consejo de Indias. Pues bien, ahora, en la Declaración, detalló que de una de las ocasiones en que estuvo al frente de dicho cargo, el mercedario fray Tomás José Suárez le debía aún 13.414 pesos "procedidos de que siendo yo Presidente de Panamá, y el dicho Padre Comendador del convento que allí tiene la religión le di en confianza diferentes cantidades de dinero como de las raciones de pan que estuvieron a su cargo, sin que entre los dos hubiese nunca cuenta formal alguna por la

Declaración 1630. AHPM, Protocolo 16.040, f. 85r.

80 Del arzobispo virrey del Perú a S.M. dando cuenta de haber publicado el nuevo orden que se ha dado sobre que los corregimientos de la provisión del virrey corran a distribución de V.M. Lima, 31-VIII-1679. AGI, Lima, 79, doc. 22. Debo este dato a la amabilidad de Antonio Luis Rodríguez Ridao.

81 La cursiva es nuestra.

82 Declaración 1630. AHPM, Protocolo 16.040, f. 86r.

83 Testamento Villarrocha. Madrid, 20-II-1730. AHPM, Protocolo 16.040, f. 79r. 
suma confianza que siempre he tenido $[\ldots]^{\prime 84}$. Incluso, haciendo referencia a haber quedado absuelto de la acusación de haber dado raciones de pan para la infantería, recordó que aún se le debían de "ese servicio" 38.000 pesos que había suplido, si bien a continuación reconoció que el mismo fraile, Tomás José Suárez, había actuado como testaferro suyo en aquella operación pues en su "cabeza y nombre se dieron las dichas raciones" ${ }^{\prime 5}$. Los textos no van más allá de esos escuetos datos pero ponen de manifiesto cómo en sus breves estancias al frente de aquel cargo político abrió diferentes frentes de negocio, que tanto por su propio título de nombramiento como por las Leyes de Indias le estaban prohibidos. De ahí, por ejemplo, el recurso a testaferros o personas de confianza, como su propio sobrino, con quien mantenía múltiples negocios, unos mediante documentos escritos, esto es, poderes notariales, en tanto que otros simplemente se basaban en relaciones de estricta confianza familiar.

Aquella Declaración posterior al testamento alumbra muchos más elementos acerca de un hombre que llegó a acumular una inmensa fortuna, tanto como para actuar de prestamista de dos virreyes del Perú. Hace ya muchos años que Domínguez Ortiz dio a conocer la compra del virreinato del Perú por parte del conde de Cañete en el año 1696, y las dificultades que este tuvo para reunir la cuantiosa suma de 250.000 escudos que ofreció por el cargo, aunque solo pudo entregar inicialmente $130.000^{86}$. Pues bien, Cañete recurrió al préstamo y entre los prestamistas estuvo el marqués de Villarocha quien, al haber muerto el conde en el Mar del Sur cuando se dirigió hacia Perú, no había cobrado aún, a la altura de 1730, la suma de 9.000 pesos que había prestado "a su excelencia para dicho virreinato" fecha indeterminada, volvió a prestar 17.500 pesos a otro virrey, el príncipe de Santo Buono, un personaje con el que tuvo estrecha amistad y con el que mantendría diversos negocios ${ }^{88}$. Prestar a quien iba a ser la autoridad superior del mismo territorio en que iba a ejercer sus cargos no era algo baladí.

En todo caso las prácticas de unos y otros individuos se asemejaban mucho. En 1713, cuando Santo Buono negoció su nombramiento como virrey, propuso a Felipe V un pacto para no "robar" demasiado, y a cambio percibir una cantidad de 600.000 pesos durante tres años consignada sobre determinados "espacios de robo", si bien luego trató de enriquecerse por los mismos procedimientos ilícitos en que habían incurrido sus predecesores ${ }^{89}$. Lo delató en la Declaración el marqués de Villarrocha cuando llegó a afirmar que "dejé y puse en poder de Manuel de Gorrachategui una porción de azogue que me remitió el Exmo. Sr. Príncipe de Santo Buono para que se lo pudiese vender a los mineros del Darién"

Pero tan interesante como la relación entre el marqués y los virreyes resulta observar las que constituían las verdaderas ocupaciones del que fuera tres veces Capitán General de Panamá ${ }^{91}$. En el momento de testar, y cuando llevaba ya largo tiempo en la Corte, sus cuentas revelan que por encima de todo era un mercader que

\footnotetext{
Declaración 1630. AHPM, Protocolo 16.040, f. 87r.-87v.

Ibídem, f. 89v.

Domínguez Ortiz, 1965: 49.

Declaración 1630. AHPM, Protocolo 16.040, f. 88r.

Ibídem, f. 84 v.

Andújar, 2008: 298.

Declaración 1630. AHPM, Protocolo 16.040, f. 88 v.

91 Excluimos de esas actividades otras de no menor importancia pero que requerirían ser tratadas por extenso. Entre ellas destacan la de prestamista para los numerosos compradores de cargos para servir en América así como la que debió ser una de las principales durante los últimos años de su vida: las inversiones en concursos de bienes.
} 
comerciaba con toda suerte de productos, principalmente con cacao -de Guayaquil-, pero también con vino, aguardiente, madera y harina. Ese abanico de productos se completaba con el tráfico de esclavos, sin duda uno de sus principales objetivos en el momento de comprar el puesto de Capitán General de Panamá, empresa en la que debió contar con quienes desde un primer momento fueron sus socios, los financieros holandeses Bartolomé Flon y Huberto de Ubrecht, los que luego cofinanciarían su empresa de levantar el regimiento de Fusileros Reales de Artillería, y lograrían un decreto del rey para deponerlo de su cargo de Panamá por la deuda que mantenía con ellos. En relación a esos esclavos, muchos años después de haber cesado por tercera vez en el cargo declaró que un tal Juan Morillo, vecino de Panamá, le debía de 3.000 a 4.000 pesos "cuya cantidad procede de los negros buzos que le vendí, obligándose a pagarle el $10 \%$ al año" de intereses ${ }^{92}$.

Lo cierto es que todas las cuentas que el marqués de Villarrocha hizo al final de sus días revelan que las acusaciones que se le hicieron durante los tres breves mandatos en los que estuvo al frente de la Presidencia de Panamá y de su Capitanía General tenían sobrados fundamentos, pero en las tres ocasiones ninguna de ellas tuvo efecto pues siempre fue absuelto por el Consejo de Indias. Cabe interrogarse pues acerca de las razones del Consejo para admitir sus cargos y declararlo libre de toda culpa, a pesar de que las acusaciones fueron reiteradas y siempre sobre los cortos periodos de mandato.

Si hasta aquí el cruce de fuentes documentales nos ha permitido obtener una dimensión del tema diferente de la registrada en los documentos públicos, para tratar de alumbrar algo de luz sobre la complejidad de la pregunta que acabamos de enunciar, recurrimos al análisis de redes que, como mínimo, nos permitirá plantear hipótesis acerca de las posibles explicaciones hacia ese favorable trato del que debió gozar el marqués de Villarrocha en el Consejo de Indias.

\section{El problema del método de investigación: la red familiar}

Se puede avanzar aún más en la investigación si desde la reflexión sobre las fuentes documentales que manejamos trasladamos el problema hacia la metodología. No vamos a extendernos en este sentido sobre la relevancia que el análisis de redes está teniendo en la historiografía de los últimos años porque una amplia producción se ha ocupado del tema ${ }^{93}$. En el caso que nos atañe, la reconstrucción del universo relacional del marqués de Villarrocha resulta imprescindible porque permite entender su trayectoria y, como veremos, en última instancia puede aportar una de las claves fundamentales para encontrar una explicación, tanto a sus actividades ilícitas cuando ocupó la Capitanía General de Panamá como sobre todo a su continua exoneración de los cargos por parte del Consejo de Indias.

La red relacional de amigos debió ser muy extensa pero carecemos de datos precisos para determinar la fuerza de los vínculos, salvo en dos casos que, por otro lado, resultan harto ilustrativos. En su Declaración denominó como su "buen amigo" a Bernardo Solís Vango, con quien mantuvo intensos contactos. Este no era otro que un reconocido comerciante y contrabandista ${ }^{94}$ que en 1708 , aprovechando

\footnotetext{
Declaración 1630. AHPM, Protocolo 16.040, f. 88 v.

Véase Ponce - Amadori, 2008.

Turiso, 2002: 330.
} 
la extraordinaria almoneda que tuvo lugar durante la Guerra de Sucesión, compró tres corregimientos en el virreinato del Perú ${ }^{95}$. Ese mismo año fue denunciado ante el Consejo de Indias por estar implicado en el cobro del 25\% de las mercancías desembarcadas en el puerto de Pisco, un negocio en el que formaba sociedad con el mismísimo virrey, el marqués de Castelldosrius, y en el que exigía ese porcentaje sobre el valor de los productos franceses que se introducían en Perú ${ }^{96}$. Justo un año después de adquirir esos cargos fue indultado por un delito de contrabando, algo que no era nuevo en su trayectoria pues ya durante el gobierno del virrey conde de la Monclova fue procesado por transportar azogue a Nueva España ${ }^{97}$. Otro amigo del marqués de Villarrocha fue el oidor que rescató a su esposa cuando fue liberada por el corsario Clipperton, Ambrosio Tomás Santaella Melgarejo, quien había accedido a una plaza de fiscal de la Audiencia de Guatemala en 1711 tras pagar por ella la suma de 7.000 pesos $^{98}$. En esa fecha ya se encontraba en la Corte el marqués de Villarrocha tras haber sido absuelto por segunda vez de sus cargos, etapa durante la cual un gran número de individuos procedentes del virreinato del Perú se hallaban a la búsqueda de sus pretensiones de cargos y honores aprovechando la extraordinaria oferta existente por entonces.

Sin embargo, el personaje que ocupa un lugar central en la historia del marqués del Villarrocha fue alguien que años después desempeñaría uno de los cargos más importantes de la monarquía, el de Presidente del Consejo de Castilla, y que acabaría titulando como marqués de Lara ${ }^{99}$. Aludimos a Nicolás Manrique de Lara, su cuñado, quien inició su carrera al servicio de la monarquía en julio de 1708 cuando compró un puesto de consejero togado supernumerario del Consejo de Indias por la considerable suma de 240.000 reales $^{100}$, un cargo de administración de justicia de los que, en teoría, no se podían vender, pero que en aquellos años entraron a formar parte del mercado venal que legitimaba la contienda sucesoria. Por entonces era un joven de unos 29 años de edad, pues había nacido en San Cristóbal de Guanique (Perú) hacia el año $1679^{101}$. En el Consejo de Indias permaneció hasta enero de 1717 en que fue reformado a causa de la nueva planta de ese año, pero cuatro años después fue compensado de la pérdida de ese cargo al ser nombrado consejero togado del Consejo de Guerra, cargo al que sumó los honores de consejero de Castilla en 1725, que iban anexos a su puesto en Guerra, y en el que permanecería hasta abril de 1742, año en que obtuvo plaza efectiva de consejero de Castilla. Por tanto, Nicolás Manrique de Lara, en el momento de adquirir la plaza de consejero de Indias no era alguien que pudiera exhibir experiencia o conocimiento en los asuntos de América. Por otro lado, al poco tiempo de llegar a la Corte hizo un ventajoso matrimonio al enlazar con María Nicolasa San Martín, hija de Manuel San Martín, secretario del Consejo de Italia, quien dotó a su hija con una escribanía de Cámara perpetua del Consejo de Castilla valorada en 600.000 reales $^{102}$.

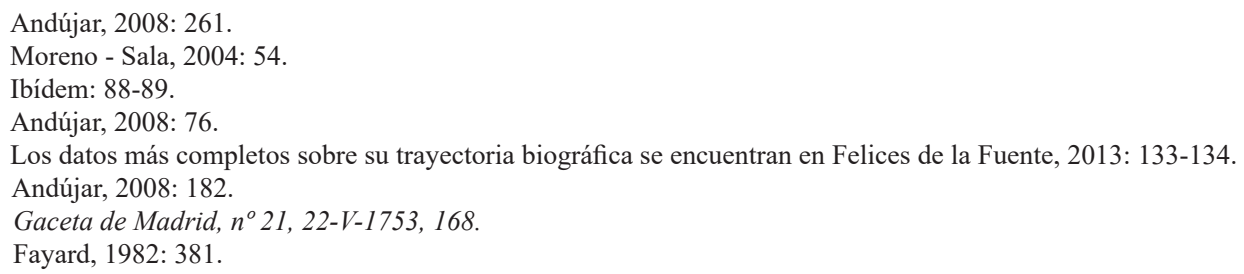


¿Facilitó la compra del puesto de consejero el marqués de Villarrocha? Lo único que sabemos es que tenía caudales suficientes como para haber prestado a su cuñado el dinero suficiente para adquirir el cargo. Años antes lo había hecho con otros individuos que beneficiaron cargos, como Juan Corral de la Banda que compró en 1698 una plaza de oidor de la Audiencia de Chile ${ }^{103}$. De todos modos, lo interesante del caso radica en que si comparamos las fechas de los tres procesos judiciales a los que fue sometido el marqués de Villarrocha constatamos que en uno de ellos fue juzgado por un tribunal, el Consejo de Indias, en el que se sentaba su propio cuñado, y en el segundo proceso ya no ejercía de consejero de Indias pero ocupaba en las proximidades del mismo un sillón de consejero de Guerra. Con tan decisivo capital relacional difícilmente se podía esperar que pudiese tener sentencias en su contra. Es más, cuando partió hacia Indias la segunda orden de su cese, en mayo de 1707, su cuñado aún no era consejero, e igualmente cuando el 10 de septiembre de 1717 se dictó la tercera orden de cese en sus cargos de Presidente de la Audiencia y Capitán General de Panamá, Nicolás Manrique de Lara se había visto obligado a dejar su puesto de consejero como consecuencia de la reforma de enero de ese mismo año. El marqués de Villarrocha, en ambas ocasiones, no pudo gozar en el Consejo de Indias de la protección directa de su cuñado.

Restaría por analizar una tercera red de relaciones, que no es otra que la de los amigos, clientes y socios de sus empresas mercantiles que depusieron en las testificaciones de los procesos en favor del marqués, pero la complejidad de esa red escapa a los límites de esta aportación. Y en sentido contrario también se podría reconstruir la red de enemigos, probablemente muchos de ellos los que se vieron afectados por la irrupción en su mismo espacio de un competidor en el contrabando y en los múltiples negocios ilícitos que por entonces tenían un lugar privilegiado en Panamá.

En todo caso, anotamos por último que el "polifacético" marqués al que aludíamos al principio de este texto, declaró en su testamento que había perdido todos sus bienes cuando fue apresado por el corsario inglés en 1720. Probablemente se refería a que había perdido aquellos bienes que portaba en el barco en aquel momento, pues tanto su testamento como la Declaración ponen de manifiesto que después de aquel año siguió manteniendo negocios en Indias -recuérdense las cuentas con su sobrino Bernabé Felipe de Aragón- y logró conservar una inmensa fortuna.

\section{A modo de conclusión}

En las páginas precedentes hemos mostrado un estudio que, más allá del caso tratado, pretende ser ante todo una reflexión sobre la interpretación de las fuentes documentales y la metodología a utilizar cuando se abordan estudios sobre dinámicas relacionadas con la corrupción. Con múltiples fuentes emanadas de los procesos judiciales a que fue sometido el marqués de Villarrocha, una historia del caso habría sido posible, pero quedaría incompleta, como se ha demostrado a partir del documento notarial que casi nunca se va a hallar en los anaqueles de los grandes depósitos de los archivos estatales. Pero al mismo tiempo el caso estudiado es una historia inacabada, de la cual aquí tan solo se presentan las líneas generales de lo que fue un proceso complejo. Como ejemplo de tal afirmación puede anotarse la necesidad de

103 Burkholder - Chandler, 1984: 207. 
estudiar en clave de análisis de redes las relaciones entre el marqués de Villarrocha y los financieros holandeses y, a su vez, las de estos con los intereses de Francia en el comercio americano en la coyuntura de la Guerra de Sucesión.

Cuando se analizan procesos históricos relacionados con la corrupción, el historiador, a menudo, debe realizar un doble proceso de indagación, uno, propio de cualquier investigación histórica, y otro, más complicado si cabe, de reconstrucción de hechos y acontecimientos que apenas han dejado huellas, o de los cuales apenas existen meros indicios. Esa doble característica obliga necesariamente a profundizar en el análisis de las fuentes, a cruzar múltiples documentos de diverso signo, y en especial a definir de forma precisa una metodología de trabajo en la que a menudo la falta de evidencias documentales debe ser suplida por mecanismos indirectos de estudio. Puede afirmarse que la ocultación, los silencios, la eliminación de datos, la manipulación de los registros, la intervención de testigos parciales, suelen ser algunas de las características habituales en los estudios sobre prácticas de cohecho, malversación de caudales públicos, sobornos, concusiones, fraudes y "excesos" en general, cometidos, en el ámbito que estudiamos, por los agentes de gobierno de la monarquía. Por ende, en ese contexto se impone tanto un análisis crítico de las fuentes documentales que se estudian como la aplicación de una metodología de investigación que permita aproximarse, en la medida de lo posible, a una realidad histórica casi siempre poco nítida.

Cuestiones de fuentes deberían estar en el punto de partida de cualquier investigación sobre historia de la corrupción. Respecto a la necesidad de acudir a múltiples fuentes, creemos que ha quedado sobradamente demostrado en el caso expuesto cuando hemos constatado que tan valiosa nos ha resultado la escueta Declaración que hizo el marqués de Villarrocha, unos días después de hacer testamento, como las miles de páginas generadas por los procesos judiciales que tuvo en el Consejo de Indias. Por lo que hace al método, apenas si hemos anotado unas líneas sobre las posibilidades del análisis de redes. Pero se puede avanzar mucho más aún si el enfoque microhistórico, que no el simple análisis de lo micro, se erige en elemento articulador de la investigación. Queda para otra ocasión, y para otro formato de publicación, una investigación que intuimos apasionante, porque puede arrojar mucha luz sobre las prácticas de corrupción en la monarquía hispánica, las formas de gobierno político, la incidencia de los procesos venales en las dinámicas de gobierno, el poder, las facciones en las luchas por el control de los recursos, los daños a terceros provocados por los abusos de los gobernantes y, en última instancia, la fragilidad de los mecanismos de control de la monarquía en territorios situados a miles de kilómetros de distancia.

Con toda esa tarea por hacer, este texto viene a ser una primera aproximación al fascinante caso del marqués de Villarrocha y al ejercicio de sus cargos en Panamá en las postrimerías del siglo XVII. Pero ante todo pretende ser una llamada de atención sobre la necesidad de reflexionar sobre los documentos que hallamos en los archivos y sobre los métodos de investigación que utilizamos. 


\section{Referencias bibliográficas}

Aguirre Rojas, Carlos Antonio. Microhistoria italiana: modo de empleo. Barcelona: Montesinos, 2014.

Álamo Martell, María Dolores. "El juicio de residencia a José Martínez de Salazar, gobernador, capitán general y presidente de la Real Audiencia de Buenos Aires (1673-1674)". Anuario de Historia del Derecho Español, no 85 (2015), 69-117.

Andújar Castillo, Francisco. El sonido del dinero. Monarquía, ejército y venalidad en la España del siglo XVIII. Madrid: Marcial Pons, 2004.

- Necesidad y venalidad. España e Indias, 1704-1711. Madrid: Centro de Estudios Políticos y Constitucionales, 2008.

- "Venalidad de oficios y honores. Metodología de investigación". En Cargos e ofícios nas Monarquías Ibéricas: provimiento, controlo e venalidade (séculos XVII e XVIII), editado por Stumpf, Roberta - Chaturvedula, Nandini. Lisboa: Centro de História de Além-Mar, 2012, 175-197.

- "The venality of offices and honors in Spain and America in the Eighteenth Century". En Serve the power (s), serve the state. America and Eurasia, editado por Garavaglia, Juan Carlos - Braddick, Michael J. - Lamouroux, Christian. Cambridge: Cambridge Scholars Publishing, 2016, 68-104.

- "Gobernar por decreto y sin Consejos en el reinado de Carlos II: patronazgo, venalidad y corrupción". En Gobernar y reformar la monarquía. 25 años de estudios sobre los agentes políticos y administrativos en España y América, editado por Bertrand, Michel - Andújar Castillo, Francisco - Glesener, Thomas. Valencia: Albatros. (En prensa, a).

- "Redes de amistad, paisanaje y venalidad de limeños en torno a los hábitos de las Órdenes Militares a finales del siglo XVII". Revista de Indias. (En prensa, b).

Andújar Castillo, Francisco - Giménez Carrillo, Domingo Marcos. "Iglesia, negocios y poder entre América, Madrid y el Reino de Granada en el siglo XVII: Bartolomé Marín de Poveda". En Riqueza, poder y nobleza: los Marín de Poveda: una historia familiar del siglo XVII vista desde España y Chile, editado por Andújar Castillo, Francisco - Giménez Carrillo, Domingo Marcos. Almería: Universidad de Almería, 2011, 179-212.

Andújar Castillo, Francisco - Gil Martínez, Francisco. "Los indultos al comercio durante la Guerra de Sucesión: la Junta de Indultos". En Comercio y cultura en la Edad Moderna, editado por Iglesias Rodríguez, Juan José - Pérez García, Rafael M. - Fernández Chaves, Manuel F. Sevilla: Universidad de Sevilla, 2015, 11091121.

Bertrand, Michel. "Penser la corruption". e-Spania, no 16 (2013). DOI: 10.4000/espania. 22807

Braddick, Michael J. "Public Office and Private Benefit in Early Modern England". En Serve the power (s), serve the state. America and Eurasia, editado por Garavaglia, Juan Carlos - Braddick, Michael J. - Lamouroux, Christian. Cambridge: Cambridge Scholars Publishing, 2016, 198-221.

Burkholder, Mark A. - Chandler, David A. De la impotencia a la autoridad: la corona española y las Audiencias en América. México: Fondo de Cultura Económica, 1984.

Cárdenas Gutiérrez, Salvador. "La lucha contra la corrupción en la Nueva España según la visión de los neoestoicos". Historia Mexicana, vol. 55, nº 3 (2006), 717-765. 
Domínguez Ortiz, Antonio. "Un virreinato en venta". Mercurio Peruano, no 453 (1965), 43-51.

Dubet, Anne. "La moralidad de los mentirosos: por un estudio comprensivo de la corrupción". En Mérito, venalidad y corrupción en España y América. Siglos XVII y XVIII, editado por Ponce Leiva, Pilar - Andújar Castillo, Francisco. Valencia: Albatros, 2016, 213-234.

Fayard, Janine. Los miembros del Consejo de Castilla (1621-1746). Madrid: Siglo XXI, 1982.

Feijoo, Benito. Theatro Crítico Universal, tomo IV. Madrid: Antonio Pérez de Soto, 1753.

Felices de la Fuente, María del Mar. Condes, Marqueses y Duques. Biografias de nobles titulados durante el reinado de Felipe V. Madrid: Doce Calles, 2013.

Fernández Durán, Reyes. La corona española y el tráfico de negros: del monopolio al libre comercio. Madrid: Ecobook, 2011.

Gagini, Carlos. "Documentos para la historia de Costa Rica". Revista de Costa Rica, $n^{\circ} 10$ (1924), 245-249.

García García, Antonio. "Corrupción y venalidad en la magistratura mexicana durante el siglo XVIII”. Illes i Imperis, nº 16 (2014), 13-37.

Herzog, Tamar. "Ritos de control, prácticas de negociación: pesquisas, visitas y residencias y Las relaciones entre Quito y Madrid". En Nuevas Aportaciones a la Historia Jurídica de Iberoamérica (CD-Rom), coordinado por Andrés-Gallego, José. Madrid: Fundación Histórica Tavera, 2000. Disponible en www.larramendi. es/i18n/catalogo imagenes/grupo.cmd?path=1000181.

Lohmann Villena, Guillermo. Los ministros de la Audiencia de Lima en el reinado de los Borbones (1700-1821). Esquema de un estudio sobre un núcleo dirigente. Sevilla: Consejo Superior de Investigaciones Científicas, 1974.

Moreno Cebrián, Alfredo. "Acumulación y blanqueo de capitales del marqués de Castelfuerte, 1723-1736”. En El 'premio' de ser virrey. Los intereses públicos y privados del gobierno virreinal en el Perú de Felipe $V$, editado por Moreno Cebrián, Alfedo - Sala i Vila, Núria. Madrid: Consejo Superior de Investigaciones Científicas, 2004, 151-290.

Moreno Cebrián, Alfredo - Sala i Vila, Núria. El 'premio'de ser virrey. Los intereses públicos y privados del gobierno virreinal en el Perú de Felipe V. Madrid: Consejo Superior de Investigaciones Científicas, 2004.

Muñoz Serrulla, María Teresa. "Don Bartolomé de Flon y Morales, I Conde de la Cadena, finanzas y ascenso social: su participación en la creación y desarrollo del Monte de Piedad de Madrid (S. XVIII)". Hidalguía: la revista de genealogía, nobleza y armas, $\mathrm{n}^{\circ} 331$ (2008), 729-770.

Peytraud, Lucien. L'esclavage aux Antilles françaises avant 1789: d'après des documents inédits des archives coloniales. París: Librairie Hachette, 1897.

Ponce Leiva, Pilar - Amadori, Arrigo. "Redes sociales y ejercicio del poder en la América hispana: consideraciones teóricas y propuestas de análisis". Revista Complutense de Historia de América, no 34 (2008), 15-42.

Ponce Leiva, Pilar. "Percepciones sobre la corrupción en la Monarquía Hispánica, siglos XVI y XVII". En Mérito, venalidad y corrupción en España y América. Siglos XVII y XVIII, editado por Ponce Leiva, Pilar - Andújar Castillo, Francisco. Valencia: Albatros, 2016, 193-211. 
Ragon, Pierre. Pouvoir et corruption aux Indes espagnoles. Le gouvernement du comte de Baños vice-roi du Mexique. París: Belín, 2016.

Reyes Cárdenas, Ana Catalina. "Corrupción, poder y abuso: el caso de los Capitanes a Guerra durante el tardío colonial en el Nuevo Reino de Granada". Historelo. Revista de Historia Regional y Local, no 9 (2013), 42-72.

Rocha, Diego Andrés. Tratado único, y singular del origen de los indios occidentales del Piru, Mexico, Santa Fé, y Chile. Lima: Imprenta de Manuel de los Olivos, 1681.

Rodríguez Moya, Inmaculada - Fernández Valle, $\mathrm{M}^{\mathrm{a}}$ de los Ángeles - López Calderón, Carme (eds.). Arte y patrimonio en Iberoamérica. Tráficos transoceánicos. Castelló de la Plana: Publicaciones de la Universidad Jaume I, 2016.

Rodríguez Ridao, Antonio. "La administración del situado en tiempos del gobernador Marín de Poveda: corrupción y venalidad en detrimento del ejército de Chile (1692-1700)". Revista Complutense de Historia de América, nº 43 (2017), 101126

Romeiro, Adriana. "A corrupçao na Época Moderna. Conceitos e desafios metodologicos". Revista Tempo, vol. 21, no 38 (2015), 1-22. DOI: 10.1590/TEM-1980542 X2015v213810

Rosenmüller, Christoph - Ruderer, Stephan. "Introducción. La nueva historia de la corrupción en América Latina". En "Dádivas, dones y dineros". Aportes a nueva historia de la corrupción en América Latina desde el imperio español a la modernidad, editado por Rosenmüller, Christoph - Ruderer, Stephan. Madrid: Iberoamericana - Vervuert, 2016, 7-25.

Sala i Vila, Nuria. "Una corona bien vale un virreinato: el marqués de Castelldosrius, primer virrey borbónico del Perú (1707-1710)". En El 'premio'de ser virrey. Los intereses públicos y privados del gobierno virreinal en el Perú de Felipe V, editado por Moreno Cebrián, Alfedo - Sala i Vila, Núria. Madrid: Consejo Superior de Investigaciones Científicas, 2004, 17-150.

Sanz Ayán, Carmen. "Financieros holandeses de Felipe V en la Guerra de Sucesión: Huberto Hubrecht”. En España y las 17 provincias de los Países Bajos: una revisión historiográfica (XVI-XVIII), tomo II, editado por Herrero Sánchez, Manuel - Crespo Solana, Ana. Madrid: Silex, 2002, 563-582.

Sanz Tapia, Ángel. ¿Corrupción o necesidad? La venta de cargos de gobierno americanos bajo Carlos II (1674-1700). Madrid: Consejo Superior de Investigaciones Científicas, 2009.

Torres Aguilar, Manuel. Corruption in the Administration of Justice in Colonial Mexico: a special case. Madrid: Dykinson, 2015.

Turiso Sebastián, Jesús. Comerciantes españoles en la Lima borbónica: anatomía de una elite de poder (1701-1761). Valladolid: Universidad de Valladolid, 2002.

Victoria Ojeda, Jorge. Corrupción y contrabando en la península de Yucatán. De la Colonia a la Independencia. Mérida: Secretaría de la Cultura y las Artes de Yucatán - Consejo Nacional para la Cultura y las Artes, 2015. 